\title{
Lessons of Risk Communication and Health Promotion - West Africa and United States
}

\author{
Sara R. Bedrosian ${ }^{1}$ \\ Cathy E. Young ${ }^{2}$ \\ Laura A. Smith, MA ${ }^{2}$ \\ Joanne D. Cox, $\mathrm{MC}^{3}$ \\ Craig Manning ${ }^{4}$ \\ Laura Pechta, $\mathrm{PhD}^{3}$ \\ Jana L. Telfer, $\mathrm{MA}^{5}$ \\ Molly Gaines-McCollom, $\mathrm{MPH}^{3}$ \\ Kathy Harben ${ }^{1}$ \\ Wendy Holmes, $\mathrm{MS}^{6}$ \\ Keri M. Lubell, $\mathrm{PhD}^{3}$ \\ Jennifer H. McQuiston, DVM ${ }^{1}$ \\ Kristen Nordlund ${ }^{2}$ \\ John O'Connor, $\mathrm{MS}^{2}$ \\ Barbara S. Reynolds, $\mathrm{PhD}^{5}$ \\ Jessica A. Schindelar, $\mathrm{MPH}^{1}$ \\ Gene Shelley, $\mathrm{PhD}^{7}$ \\ Katherine Lyon Daniel, $\mathrm{PhD}^{5}$ \\ ${ }^{1}$ Division of Public Affairs, Office of the Associate Director for Communication, CDC \\ ${ }^{2}$ Office of the Director, National Center for Emerging and Zoonotic Infectious Diseases, CDC \\ ${ }^{3}$ Division of Emergency Operations, Office of Public Health Preparedness and Response, CDC \\ ${ }^{4}$ Division of High-Consequence Pathogens and Pathology, National Center for Emerging and Zoonotic Infectious Diseases, CDC \\ ${ }^{5}$ Office of the Director, Office of the Associate Director for Communication, CDC \\ ${ }^{6}$ Office of the Director, Office for State, Tribal, Local, and Territorial Support, CDC \\ ${ }^{7}$ Division of HIVIAIDS Prevention, National Center for HIVIAIDS, Viral Hepatitis, STD, and TB Prevention, CDC
}

Corresponding author: Sara Bedrosian, Division of Public Affairs, Office of the Associate Director for Communication, CDC. Telephone: 404-639-0677; E-mail: eri7@cdc.gov.

\section{Summary}

During the response to the 2014-2016 Ebola virus disease (Ebola) epidemic in West Africa, CDC addressed the disease on two fronts: in the epidemic epicenter of West Africa and at home in the United States. Different needs drove the demand for information in these two regions. The severity of the epidemic was reflected not only in lives lost but also in the amount of fear, misinformation, and stigma that it generated worldwide. CDC helped increase awareness, promoted actions to stop the spread of Ebola, and coordinated CDC communication efforts with multiple international and domestic partners. CDC, with input from partners, vastly increased the number of Ebola communication materials for groups with different needs, levels of health literacy, and cultural preferences. CDC deployed health communicators to West Africa to support ministries of health in developing and disseminating clear, science-based messages and promoting science-based behavioral interventions. Partnerships in West Africa with local radio, television, and cell phone businesses made possible the dissemination of messages appropriate for maximum effect. CDC and its partners communicated evolving science and risk in a culturally appropriate way to motivate persons to adapt their behavior and prevent infection with and spread of Ebola virus. Acknowledging what is and is not known is key to effective risk communication, and CDC worked with partners to integrate health promotion and behavioral and cultural knowledge into the response to increase awareness of the actual risk for Ebola and to promote protective actions and specific steps to stop its spread.

The activities summarized in this report would not have been possible without collaboration with many U.S. and international partners (http://www.cdc.gov/vhflebolaloutbreaks/2014-west-africalpartners.html).

\section{Background}

During an emergency response, communication is often the first activity as responders mobilize (1). During the 2014-2016 Ebola virus disease (Ebola) epidemic in West Africa, CDC's response focused on two fronts, the epidemic epicenter in West Africa and at home in the United States. Media coverage and public opinion drove the demand for information in the United States, whereas in West Africa, the need for life-saving information was crucial. The numbers of persons infected and 
lives lost, as well as the amount of fear, misinformation, and stigma that Ebola generated worldwide, reflected the severity of the epidemic.

Although CDC has worked with partners to develop and implement communication messages and products for international groups of intended recipients during many other public health emergencies and responses, some difficulties faced in the Ebola response in West Africa were different from those faced during previous, smaller occurrences (e.g., responding to fear of Ebola as it spread for the first time in densely populated urban settings in a region unfamiliar with the disease) (2). CDC supported the domestic and international responses by providing timely, customized messages for groups of recipients in West Africa and in the United States so communities could understand how to protect themselves and journalists could report accurate information quickly. CDC needed to depict information differently for each group: more abstractly for those in the United States and more literally for those in West Africa. For example, symptoms of Ebola were illustrated differently for each group (3). CDC's communicators worked closely with counterparts in West Africa and in the United States to develop core messages that could be customized for different countries and groups during different phases of the response. Experts in communication, education, anthropology, and behavioral science helped support the ministries of health $(\mathrm{MoHs})$ in the countries in West Africa most affected by Ebola, as well as partners to ensure that communities could obtain the information they needed to protect themselves through multiple channels (e.g., radio, cell phone text messages, posters and billboards, and face-to-face visits).

CDC has supported successful responses to Ebola for almost 40 years, since the first recognized outbreak of Ebola in Zaire in 1976, but those outbreaks occurred in remote areas of East and Central Africa, were small, and usually were contained quickly (4). The size and scope of the West African epidemic were unprecedented (5). At the start of the response, CDC's communication products were complex and text-based and did not contain much information that persons could act on to protect themselves from getting Ebola (G). As media coverage of Ebola, and the spread of the disease itself, expanded, the public's need for information outpaced the ability of public health officials to respond (7). When the first case of Ebola was diagnosed in the United States in Dallas, Texas, the U.S. public's resulting fear was disproportionate to the actual risk (8). In contrast, in West Africa, lack of understanding that germs spread disease led to belief that Ebola had causes other than a virus (e.g., witchcraft); this lack of understanding initially hindered public health efforts and contributed to the spread of the disease $(9,10)$. MoHs, CDC, and their partners needed to launch and sustain coordinated communication efforts to address community needs in West Africa; CDC and state and local departments of health and their partners needed a communication approach to address needs in the United States. These efforts involved parallel, but different, approaches on the basis of the different cultures, available communications technologies, and circumstances in West Africa and the United States.

\section{Communicating in West Africa}

Before the 2014-2016 Ebola epidemic, Guinea, Liberia, and Sierra Leone did not have the public health infrastructure and corresponding risk communication experience needed for this epidemic. These countries had never experienced a case of Ebola, and the world had never seen an epidemic of this magnitude; collectively, the global public health community lacked experience in how to address this epidemic $(11,12)$. Differences in governments, cultures, religions, languages, and tribes made having a single communication approach nearly impossible. Adding to these difficulties was a strong tradition of oral communication and a need for clear and literal illustrations that were also culturally appropriate. To be useful, communication materials had to be customized to accommodate different literacy levels, languages and dialects, and beliefs.

The number of languages and dialects spoken in the three countries that were most heavily affected demonstrates one impediment to communicating with West Africa's diverse populations. Guineans speak an estimated 36 languages comprising 59 dialects; Liberians an estimated 31 languages comprising 100 dialects; and Sierra Leoneans an estimated 25 languages comprising 76 dialects (13). Each country has an official language that was used for nationwide messaging (English for Liberia and Sierra Leone, French for Guinea), but many West Africans speak the official language as their second or third language (14), and literacy levels are among the lowest in the world. Literacy levels among persons aged $\geq 15$ years for Guinea (30.4\%), Liberia (47.6\%), and Sierra Leone (48.1\%) are much lower than the global average $(84.0 \%)$ and that of the United States $(99.0 \%)(15,16)$. Women in the three countries, who are often caregivers for the sick, have much lower literacy rates than men (Guinea: $22.8 \%$ for women, $38.1 \%$ for men; Liberia: $32.8 \%$ for women, $62.4 \%$ for men; Sierra Leone: $37.7 \%$ for women, $58.7 \%$ for men) (15). Thus, health communication teams created predominately pictorial communication materials (3) and needed to engage with knowledgeable in-country partners to develop appropriate communication messages and materials with little existing communication research about the barriers persons faced, 
information on how they were interpreting messages, or the types of attitudes and values that needed to be activated to support behavior change (17).

Before this epidemic, Ebola was unknown in West Africa and so did not seem real for many persons until their family members and neighbors died of the disease (18). CDC and partners had to address beliefs that Ebola was caused by witchcraft or by something other than a virus; mistrust of outsiders; and cultural practices that contributed to the spread of the virus before responders could effectively implement public health interventions that are known to stop an outbreak (18). Instances of disbelief in Ebola, coupled with strong cultural traditions (e.g., caring for the sick at home, seeking care from traditional healers, washing and burying the dead) increased the risk for Ebola transmission (19-21). Fear, stigma, and superstition also complicated implementation of standard public health practices. Residents hid the sick and fled communities, breaking quarantine, because of social stigma surrounding Ebola; this stigma even extended to survivors who were no longer contagious but were still shunned by their communities. In addition, ill persons avoided Ebola treatment units and ambulances because they feared dying of Ebola, turned to traditional healers to counter what they believed to be witchcraft, and at times defied recommendations from public health authorities because of fear that those authorities were responsible for spreading Ebola through apparent cause and effect $(2,22)$.

Lack of effective dialogue with communities and lack of public health resources early in the response inflamed public distrust of authorities (23) and outsiders. For example, the government of Liberia advised persons with symptoms of Ebola to seek immediate care at hospitals and clinics, but these facilities lacked sufficient numbers of beds and trained staff to care for the rapidly growing number of sick persons (24). CDC medical anthropologists supported response teams with rapid field assessments of community perceptions to guide message development and culturally appropriate information delivery (CDC, unpublished data, 2015).

Changing the behaviors that fueled the epidemic required each country to develop its own approach for adapting traditions and promoting protective actions that often ran counter to fundamental beliefs and day-to-day practices. In one example from Liberia, President Ellen Johnson Sirleaf expressed a national goal to have no new cases of Ebola by Christmas 2014. In just 8 days after this announcement, CDC and partners worked with the Liberian Ministry of Health and Social Welfare to rapidly launch a national communication campaign, Ebola Must $G O$, based on specific interventions demonstrated to stop Ebola (25). By that time in the response, adequate Ebola treatment unit beds, ambulances, and rapid response teams were available in Liberia, so the campaign focused on protective actions that persons could take until help arrived. The campaign included the message "Stopping Ebola is Everybody's Business" (25), which was a twist on a Liberian taboo: Che-che-polay (i.e., being a busybody). To address this taboo, this message in the campaign was designed to encourage persons to connect with their neighbors to show caring and to strengthen their community.

In another example from Sierra Leone, in mid-2014 the public was initially inundated with complex information about Ebola transmission (CDC, unpublished data, 2015). Recognizing the need to simplify and coordinate messaging, CDC and partners worked with the Sierra Leone National Ebola Response Centre to launch the Ebola Big Idea of the Week campaign on November 10, 2014. Approximately 80 radio, television, and print journalists from across the country were trained by experts on critical communication topics from $\mathrm{CDC}$ and other partner organizations. The campaign focused on one culturally sensitive message each week (e.g., practicing safe burials, getting early treatment, supporting survivors to defuse stigma), engaged official and unofficial spokespersons, and used a wide range of available communication channels. This media campaign was extended through October 2015 and complemented numerous social mobilization and community engagement efforts.

In Guinea, coordinated communication strategies addressed cultural differences and focused on identifying trusted local spokespersons and Ebola survivors who could relate to diverse communities. These spokespersons were paired with Frenchspeaking staff members from CDC and partner organizations to convey messages about protective behaviors and the need for changes in established traditions to avoid further spread of disease. Messages were adjusted for a specific community and were provided to trusted community members who in turn conveyed the messages to ensure greater attention and adherence to recommendations (26).

All of these activities were conducted in the context of a coordinated global communication effort that included CDC working with in-country partners, such as $\mathrm{MoH}$, humanitarian aid organizations, and other international partners. This response spanned many countries and numerous stakeholders, each with its own culture, allegiances, way of offering support, and experience in West Africa. Central to the response was collaboration with these partners to deliver coordinated messages and avoid duplication of effort while respecting individuals and communities. 


\section{Communicating in the United States}

Before the West Africa epidemic, Ebola was perceived in the United States as a distant threat that the media and entertainment industries had dramatized $(27,28)$. When two infected U.S. clinicians who had worked in Liberia were brought to the United States for treatment in August 2014, some Americans questioned the wisdom of bringing patients with Ebola to the United States; they believed themselves to be at risk for the illness from those patients (29), and media reports and traffic to the CDC Ebola website soared (Figure). Around-the-clock news coverage of the escalating Ebola crisis reinforced and heightened public concern to the point of alarm when patients came to the United States $(30,31)$.

Although the risk for Ebola transmission in the United States was low, the U.S. public began to view the disease as a serious threat to the nation's health and security (32). The fear of a U.S. epidemic required a massive communication effort by $\mathrm{CDC}$, larger than for any previous emergency response. To address this fear, messages intended to reassure (e.g., U.S. hospital capacity to manage a case of Ebola) and reduce anxiety increased confusion and mistrust when Ebola developed in two U.S. hospital workers (33).
As news of the epidemic in West Africa spread and aid workers returned to the United States, so did fear, and the rumors and stigma that arose from it affected both returning aid workers and persons from Africa living in or visiting the United States (34). Many Ebola responders faced hostility upon their return from West Africa; were ostracized by friends, families, and communities; and felt the effects of stigma at work or elsewhere (CDC, unpublished data, October 2015). For example, when some states indicated they would impose mandatory 21-day quarantines for health care workers returning from West Africa, the American Nurses Association urged "authorities to refrain from imposing more restrictive conditions than indicated in CDC guidelines, which will only raise the level of fear and misinformation" (35).

An assistant principal was asked to stay home from school for 21 days because she visited South Africa, approximately 5,000 miles away from the epidemic (36). In one state, parents would not allow their children to go to school because the principal had attended a funeral in Africa, even though that part of Africa did not have Ebola cases (37). In response to fear of Ebola that extended to CDC staff returning from West Africa, CDC and the Georgia Department of Public Health

FIGURE. U.S. news media stories* and CDC Ebola webpage ${ }^{\dagger}$ views, by day — July 21-December 31, 2014§

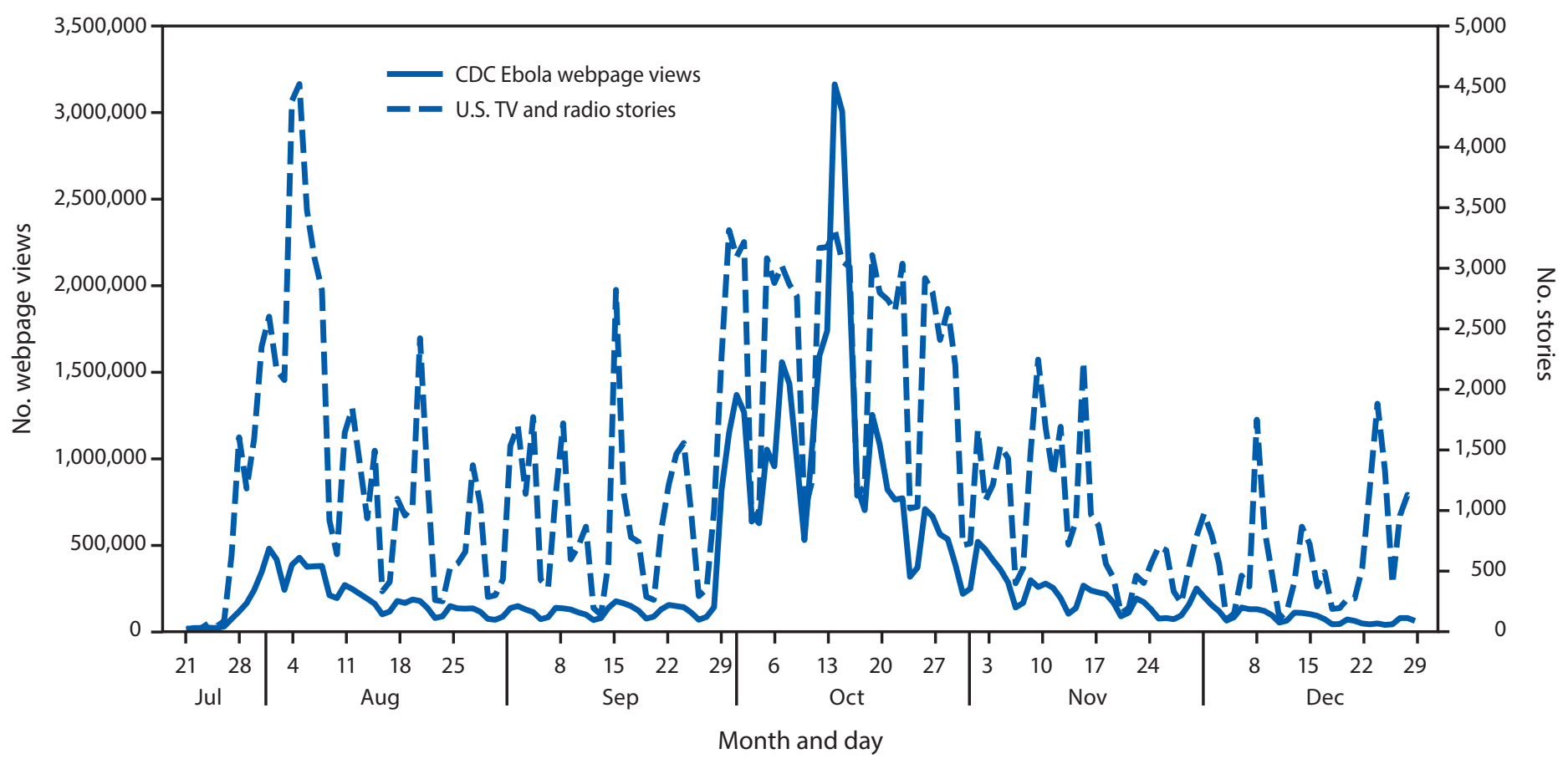

Sources: National Center for Emerging and Zoonotic Infectious Diseases, CDC (webpage views); MetroMonitor (news media stories). Abbreviations: Ebola = Ebola virus disease; TV = television.

* TV and radio news that mentioned Ebola.

† Daily number of visits to all CDC webpages related to Ebola.

$\S$ August 4: Second U.S. aid worker with Ebola arrives in United States for treatment. October 1-2: First case of Ebola diagnosed in the United States, in Dallas, Texas; CDC webpage views spike. October 13-15: Ebola diagnosed in two nurses in Dallas; at a news conference, CDC asks airline passengers who flew with one of the nurses to contact CDC; contact tracing begins in Ohio; President Barack Obama vows more aggressive Ebola response. 
jointly wrote a guidance letter to Georgia educators (38). This letter explained Ebola transmission and reassured Georgia educators about the measures being taken to protect their safety. The letter encouraged Georgia schools to allow children of asymptomatic travelers returning from countries affected by Ebola to continue attending class and encouraged the return to school of faculty or other school workers who had traveled to West Africa and were asymptomatic.

Universities canceled speaking engagements for persons who had recently visited West Africa (39). ABC News' chief medical correspondent and former CDC Acting Director Richard Besser, MD, was asked to conduct a talk through Skype, rather than speak in person, at a conference after he returned from Liberia. Dr. Besser said, "The level of risk posed by my appearance was vanishingly small, but fear won anyway. I turned them down. I did not want to feed the idea that anyone who has been to West Africa, even if not sick, poses a risk. You cannot catch Ebola in a lecture hall hearing about the power of communication during a public health crisis. What we need to do is communicate, as strongly and as often as we can, what the real risks are and aren't" $(40)$.

During the Ebola response, the media and the public challenged simple health risk messages. The lack of relevant messages about actions the public could take to protect itself led to speculation that resulted in rumors and seeking of cures or other protective measures. For example, in November 2014, news media erroneously reported that CDC quarantined a Texas turkey farm because the turkeys were infected with Ebola (41). Other rumors capitalized on the public's fear by promoting cures (e.g., vitamin C) (42-44) and selling products marketed as Ebola prevention (e.g., Ebola virus protection kits) $(43,45)$. Calls and e-mails flooded CDC; for example, during October 2014, CDC-INFO received 24,827 calls and e-mails compared with 1,801 during September 2014. These inquiries asked whether mosquitoes could spread Ebola; expressed concerns about Ebola virus in products from Africa (e.g., soap, food); and suggested remedies for Ebola (e.g., soda, herbal teas and garlic) (CDC, unpublished data, 2014). CDC continually addressed these rumors with additional communication products and messages that sought to counter fears of Ebola spreading through handshakes, pets, or mosquitoes, for instance, with facts about transmission (46).

To outpace the fear-based messages on the news and social media sites and in communities in the United States, CDC and partners worked to educate a wide range of specific groups, including clinicians, school administrators, airport staff, businesses and their employees, West Africans in the United States, and community organizations. The challenge was to balance the communication needs of persons most likely to contact a person with Ebola (health care workers, travelers to outbreak countries) and the anxiety Ebola caused for persons at little or no risk. CDC held Twitter and Facebook chats; produced infographics, fact sheets, videos, public service announcements, podcasts, and guidelines at an unprecedented pace; and handled many interactive public events (e.g., press briefings), interviews, and telephone and e-mail inquiries from the media and the public. CDC engaged with persons and organizations representing West Africans living in the United States through regular conference calls on health protection messages that they were then encouraged to share with family and friends in their home countries. These activities, along with the containment of Ebola cases in Dallas and New York City, corresponded with a decrease in information seeking, as shown by webpage views decreasing despite high media interest (Figure). The response in the United States required intense focus to ease public concern at the same time CDC's human resources were stretched as health communicators, educators, and others deployed to West Africa, sometimes multiple times.

\section{Lessons Learned}

For almost 40 years, since the 1976 Ebola outbreak in Zaire, CDC has responded to Ebola outbreaks. However, the 2014-2016 epidemic in West Africa pushed the limits of CDC's knowledge and ability to communicate necessary information, not only in West Africa but also in the United States and globally. Working partnerships with $\mathrm{MoHs}$ and other local counterparts in West Africa were essential, as were collaborations with numerous U.S. partners, including many federal, state, and local agencies.

In societies where news outlets need to fill 24 hours every day and social media channels make reporting almost instantaneous, new strategies may be needed in the application of risk communication principles to avoid an information void that, in the absence of a constant flow of clear, science-based messages, becomes filled with speculation (47).

Response to this epidemic also required integration of health promotion and anthropology with more traditional public health functions. Anthropologists are experts in cultural knowledge; their role as cultural translators benefitted this public health crisis. Earlier inclusion of anthropologists into the 2014-2016 Ebola response might have facilitated earlier community involvement and insight into factors contributing to resistance to public health interventions (e.g., the need to formally engage traditional leaders and community volunteer groups).

Some of CDC's more memorable campaigns during the response involved engaging groups (e.g., journalists and local leaders in affected communities) as part of the life-saving message development and delivery effort, rather than simply 
as receivers of information. Understanding these audiences' perspectives and actively engaging them in finding solutions was critical. Likewise, establishing strong partnerships with other organizations (e.g., those serving West African communities living in the United States) ultimately expanded the reach of public health messaging when broad reach was essential to slowing disease transmission (19).

During this response, information about Ebola constantly evolved, and health communication messages and products needed to keep pace. For example, as the response unfolded, new developments in vaccines and therapeutic drugs (48) and increasing evidence of viral persistence in body fluids of survivors and of possible sexual transmission $(49,50)$ required new messages. Responding agencies, such as CDC, need to recognize and acknowledge publicly that a key component of accurate messaging (i.e., scientific knowledge) will evolve during any response.

CDC had to balance rushing critical communication resources to Guinea, Liberia, Mali, Nigeria, and Sierra Leone to help spread life-saving health protection messages with maintaining the resources needed domestically to assuage fears when Ebola was diagnosed in this country. The agency learned that it had to devote sufficient attention and resources to each front, a lesson it must apply in future global epidemic responses. For $\mathrm{CDC}$ to adequately support $\mathrm{MoHs}$ and partners during large outbreaks, it needs a large enough pool of health communication specialists, health educators, and behavioral scientists who have the training (in incident management systems, plain language communication, risk communication, and cultural competency) and readiness (fluency in local languages, predeployment training, and vaccinations) required to deploy.

Finally, CDC and other response partners must continue to adhere to plain language and clear communication standards, including revising materials to meet the needs of each group of intended recipients. To address the difficulties presented by the specific needs of local populations, CDC must collaborate with partners to build and share a coordinated body of communication-based research, demographic data, and information about how communities in different countries understand and process information.

\section{Conclusion}

Communication is an essential part of sustainable preparedness and long-term global health security. The Ebola epidemic demonstrated that tailored, culturally appropriate communication is one of the first activities responders use as new threats emerge, especially when public fear outpaces information that persons can use to protect themselves (51). Behavioral and communication sciences also are essential to persuade the public to suspend traditions, entrust their sick family and friends to strangers, and remain in isolation to protect themselves and others, even during critical times such as harvests.

This epidemic increased global knowledge about Ebola and resulted in the need for communication about newly discovered information, particularly related to survivors. New messaging about the possibility of sexual transmission from survivors, family planning, and maternal health is continuously being developed and updated to reflect the latest scientific data and needs to be balanced with reducing stigmatization of survivors. $\mathrm{CDC}$ communication developed for this response will continue to provide information for global health security capacity building long after the end of the West Africa Ebola epidemic; going forward, culturally appropriate risk communication and health promotion need to be central to this work.

\section{References}

1. Rhoads SJ, Bush E, Haselow D, et al. Mobilizing a statewide network to provide Ebola education and support. Telemed J E Health 2015;22:153-8.

2. Roca A, Afolabi MO, Saidu Y, Kampmann B. Ebola: a holistic approach is required to achieve effective management and control. J Allergy Clin Immunol 2015;135:856-67. http://dx.doi.org/10.1016/j.jaci.2015.02.015

3. CDC. Infographics and illustrations. http://www.cdc.gov/vhf/ebola/ resources/infographics.html

4. CDC. Ebola outbreaks 2000-2014. http://www.cdc.gov/vhf/ebola/ outbreaks/history/summaries.html

5. CDC. Outbreaks chronology: Ebola virus disease. http://www.cdc.gov/ vhf/ebola/outbreaks/history/chronology.html

6. CDC. Ebola virus disease. http://www.cdc.gov/vhf/ebola/pdf/ebolafactsheet.pdf

7. Frieden TR, Damon IK. Ebola in West Africa-CDC's role in epidemic detection, control, and prevention. Emerg Infect Dis 2015;21:1897-905. http://dx.doi.org/10.3201/eid2111.150949

8. Gilsinan K. "An epidemic of fear": Ebola in the United States. The Atlantic. October 30, 2014. http://www.theatlantic.com/international/ archive/2014/10/an-epidemic-of-fear-ebola-in-the-united-states/382158/

9. Hill M. Ebola virus in West Africa. August 8, 2014. http://anthropology. msu.edu/anp204-us14/2014/08/08/ebola-virus-in-west-africa/

10. Rajewski G. What drives Ebola. TuftsNow. August 11, 2014. http:// now.tufts.edu/articles/what-drives-ebola

11. UNICEF. Misconceptions fuel Ebola outbreak in West Africa. July 11, 2014. http://www.unicef.org/media/media_74256.html

12. World Health Organization. Factors that contributed to undetected spread of the Ebola virus and impeded rapid containment. January 2015. http:/www.who.int/csr/disease/ebola/one-year-report/factors/en/

13. Ethnologue. Languages of the world: Western Africa. Dallas, TX: SIL International Publications. 2016. http://www.ethnologue.com/region/WAF

14. McArthur T. Concise Oxford companion to the English language: West African English. 1998. http://www.encyclopedia.com/doc/1O29WESTAFRICANENGLISH.html

15. Central Intelligence Agency. The world factbook. https://www.cia.gov/ library/publications/resources/the-world-factbook/

16. World by Map. Literacy rates of the countries of the world. 2015. http:// world.bymap.org/LiteracyRates.html 
17. Long C. Health Communication Capacity Collaborative blog: misinformation and lack of communication can be key drivers of a deadly disease. September 4, 2014. Baltimore, MD: Johns Hopkins Bloomberg School of Public Health. http://healthcommcapacity.org/ misinformation-lack-communication-can-key-drivers-deadly-disease/

18. Millman J. Wonkblog: the inevitable rise of Ebola conspiracy theories. The Washington Post. October 13, 2014. https://www.washingtonpost.com/news/ wonkblog/wp/2014/10/13/the-inevitable-rise-of-ebola-conspiracy-theories/

19. World Health Organization. Ebola response: what needs to happen in 2015. http://www.who.int/csr/disease/ebola/one-year-report/responsein-2015/en/

20. Focus1000; UNICEF; Catholic Relief Services. Study on public knowledge, attitudes, and practices relating to Ebola virus disease (EVD) prevention and medical care in Sierra Leone. September 2014. http:// reliefweb.int/sites/reliefweb.int/files/resources/Ebola-Virus-DiseaseNational-KAP-Study-Final-Report_-final.pdf

21. Kobayashi M, Beer KD, Bjork A, et al. Community knowledge, attitudes, and practices regarding Ebola virus disease-five counties, Liberia, SeptemberOctober, 2014. MMWR Morb Mortal Wkly Rep 2015;64:714-8.

22. Nossiter A. Fear of Ebola breeds a terror of physicians. The New York Times. July 27, 2014. http://www.nytimes.com/2014/07/28/world/ africa/ebola-epidemic-west-africa-guinea.html?_r=2

23. WHO Ebola Response Team. Ebola virus disease in West Africa-the first 9 months of the epidemic and forward projections. N Engl J Med 2014;371:1481-95. http://dx.doi.org/10.1056/NEJMoa1411100

24. Lewnard JA, Ndeffo Mbah ML, Alfaro-Murillo JA, et al. Dynamics and control of Ebola virus transmission in Montserrado, Liberia: a mathematical modelling analysis. Lancet Infect Dis 2014;14:1189-95. http://dx.doi.org/10.1016/S1473-3099(14)70995-8

25. World Health Organization. Ebola must go! 2014. http://www.afro. who.int/en/liberia/press-materials/item/7247-ebola-must-go.html

26. World Health Organization. Involving everyone: social mobilization is key in an Ebola outbreak response in Guinea. May 2014. http://www. who.int/features/2014/social-mobilisation/en/

27. Harvard School of Public Health News. Poll: most believe Ebola likely spread by multiple routes, including sneezing, coughing. [Press release]. Boston, MA: Harvard University, October 15, 2014. http://www.hsph.harvard.edu/news/ press-releases/poll-finds-most-believe-ebola-spread-by-multiple-routes/

28. Smith S. The roots of our Ebola fears. http://www.cnn.com/2014/08/06/ health/ebola-epidemic-fears/

29. Fox M. Is it safe to bring Ebola victims to the U.S.? NBC News. August 2, 2014. http://www.nbcnews.com/storyline/ebola-virus-outbreak/ it-safe-bring-ebola-victims-u-s-n170731

30. Towers S, Afzal S, Bernal G, et al. Mass media and the contagion of fear: the case of Ebola in America. PLoS One 2015;10:e0129179. http:// dx.doi.org/10.1371/journal.pone.0129179

31. Rübsamen N, Castell S, Horn J, et al. Ebola risk perception in Germany, 2014. Emerg Infect Dis 2015;21:1012-8. http://dx.doi.org/10.3201/ eid2106.150013

32. SteelFisher GK, Blendon RJ, Lasala-Blanco N. Ebola in the United States_public reactions and implications. N Engl J Med 2015;373:789_ 91. http://dx.doi.org/10.1056/NEJMp1506290

33. Sharfstein JM. On fear, distrust, and Ebola. JAMA 2015;313:784. http:// dx.doi.org/10.1001/jama.2015.346

34. AHC Media. Bioethics panel: Ebola quarantines of asymptomatic health workers "morally wrong." May 1, 2015. http://www.ahcmedia.com/ articles/135254-bioethics-panel-ebola-quarantines-of-asymptomatichealth-workers-morally-wrong
35. American Nurses Association. ANA supports CDC guidance, not mandatory quarantine for health care professionals returning from treating Ebola patients in West Africa. October 29, 2014. http://nursingworld. org/ANA-Supports-CDC-Guidance-Not-Mandatory-Quarantine

36. Associated Press. Stokes County assistant principal in South Africa raises concerns over Ebola. Winston-Salem Journal. October 21, 2014. http:// www.journalnow.com/news/state_region/stokes-county-assistantprincipal-in-south-africa-raises-concerns-over/article_1f340f26-592411e4-82db-001a4bcf6878.html

37. Agence France-Presse. Fearing Ebola, some US communities take steps. October 18, 2014. https://www.yahoo.com/news/fearing-ebola-uscommunities-dramatic-steps-152044339.html?ref=gs

38. Georgia Department of Public Health. Ebola virus diseases [Letter]. Atlanta, GA: Georgia Department of Public Health. October 6, 2014. https://www.gadoe.org/Curriculum-Instruction-and-Assessment/CTAE/ Documents/Ebola-K-12-guidance-letter.pdf

39. McKenna M. Ebolanoia: the only thing we have to fear is Ebola fear itself. Wired. October 22, 2014. http://www.wired.com/2014/10/ebolanoia/

40. Besser RE. Fight fear of Ebola with the facts [Opinion]. The Washington Post. October 15, 2014. https://www.washingtonpost.com/opinions/ richard-e-besser-fight-fear-of-ebola-with-the-facts/2014/10/15/ dba7bd1e-5399-11e4-809b-8cc0a295c773_story.html

41. Daily Buzz Live. Texas turkey farm contaminated with Ebola, over 250,000 holiday turkeys infected. November 10, 2014. http://dailybuzzlive.com/ texas-turkey-farm-contaminated-ebola-holiday-turkeys-infected/\#

42. NationalPublicRadio. FDAcracksdownonfakeEbolacuressoldonline.October23, 2014. http://www.npr.org/sections/health-shots/2014/10/23/358318848/ fda-cracks-down-on-fake-ebola-cures-sold-online

43. Leonard K. Ebola scams hit the web. U.S. News. October 16, 2014. http:// www.usnews.com/news/articles/2014/10/16/ebola-scams-hit-the-web

44. Better Business Bureau. Be wary of fraudulent healthcare products and other Ebola-related scams. October 15, 2014. http://www.bbb.org/ memphis/news-events/bbb-warnings/2014/be-wary-of-fraudulenthealthcare-products-and-other-ebola-related-scams/

45. Boyle L. "All you'll need a hazmat suit for is Halloween": doctors slam surge in useless online "Ebola survival kits" as America panic buys. Daily Mail. October 9, 2014. http://www.dailymail.co.uk/news/article-2786556/ All-1l-need-Hazmat-suit-Halloween-Doctors-slam-surge-useless-onlineEbola-survival-kits-America-panic-buys.html

46. CDC. Top 10 things you really need to know about Ebola. http://www. catawbacountync.gov/phealth/immunize/top10ebola.pdf

47. Fung IC, Tse ZT, Cheung CN, Miu AS, Fu KW. Ebola and the social media [Letter]. Lancet 2014;384:2207. http://dx.doi.org/10.1016/ S0140-6736(14)62418-1

48. Hersey S, Martel LD, Jambai A, et al. Ebola virus disease-Sierra Leone and Guinea, August 2015. MMWR Morb Mortal Wkly Rep 2015;64:9814. http://dx.doi.org/10.15585/mmwr.mm6435a6

49. World Health Organization. Interim advice on the sexual transmission of the Ebola virus disease. January 21, 2016. http://www.who.int/ reproductivehealth/topics/rtis/ebola-virus-semen/en

50. Christie A, Davies-Wayne GJ, Cordier-Lassalle T, et al. Possible sexual transmission of Ebola virus-Liberia, 2015. MMWR Morb Mortal Wkly Rep 2015;64:479-81. Erratum in: MMWR Morb Mortal Wkly Rep 2015;64:1180.

51. ScienceNet. What Ebola taught us about risk communication. September 26, 2014. http://www.scienceonthenet.eu/content/article/michele-bellone/ what-ebola-taught-us-about-risk-communication/september-2014 